\title{
(2) OPEN ACCESS \\ How bad are life expectancy trends across the UK, and what would it take to get back to previous trends?
}

\author{
Jon Minton (1), ${ }^{1}$ Eilidh Fletcher, ${ }^{2}$ Julie Ramsay ${ }^{0},{ }^{3}$ Kirsty Little, ${ }^{4}$ Gerry McCartney (1D)
}

\author{
${ }^{1}$ Public Health Observatory, \\ Public Health Scotland, \\ Glasgow, UK \\ ${ }^{2}$ Public Health Scotland, \\ Edinburgh, UK \\ ${ }^{3}$ Vital Events Statistics, National \\ Records of Scotland, Edinburgh, \\ UK \\ ${ }^{4}$ Public Health Wales, \\ Cardiff, UK
}

Correspondence to Dr Gerry McCartney, Public Health Observatory, NHS Health Scotland, Glasgow G2 6QE, UK; gmccartney@nhs.net

Received 5 February 2020

Revised 5 April 2020

Accepted 21 April 2020
Check for updates

(C) Author(s) (or their employer(s)) 2020. Re-use permitted under CC BY-NC No commercial re-use. See rights and permissions. Published by BMJ.

To cite: Minton J, Fletcher E, Ramsay J, et al. J Epidemiol Community Health

2020;74:741-746.

\begin{abstract}
Background Within the UK, there has been debate on whether life expectancy is increasing or decreasing in particular single or 3-year periods, but there has been less thinking whether overall trends have changed. This paper considers the extent to which the trends in life expectancy for the UK and its nations have changed before and after 2011.

Methods We used the Office for National Statistics period life expectancy data for the UK and its nations. We used Lee's approach to project life expectancy based on repeated sampling of year-to-year change in the baseline periods (1990-2011 and 1980-2011) and applied that to 2012 onwards.
\end{abstract}

Findings Improvements in period life expectancy were substantially and consistently lower between 2012 and 2018 than predicted from the trends from 1980 and, especially, from 1990. By 2018, life expectancy was lower than projected for females and males, respectively, by 1.22 and 1.52 years (England), 1.44 and 0.95 years (Northern Ireland), 1.30 and 1.44 years (Scotland), 1.53 and 1.63 years (Wales) and 1.24 and 1.49 years (UK overall), based on the 1990-2011 baseline period. Using a longer baseline period, which includes the slower rates of improvement during the 1980s, slightly reduces the gap between the current life expectancies and the projected medians.

Interpretation Future academic and policy focus should be on the deviation of the life expectancy trends from the baseline projection rather than on year-to-year variation. Concerted policy focus to return life expectancy to the projected trends is now urgently required.

\section{INTRODUCTION}

Life expectancy at birth improved continuously from 1950 to 2010 across most high-income countries. ${ }^{12}$ However, some of these countries subsequently experienced slower life expectancy improvements, and in some cases a decline. ${ }^{34}$ The UK, USA and the Netherlands have been some of the countries experiencing the most profound changes in trends, but many other countries (including Denmark, much of Eastern Europe, Korea and Japan) have continued to experience improving trends.

Much of the early discussion about the trends focused on the extent to which this was due to higher deaths in a single year or winter period. ${ }^{6} 7$ This was largely due to concerns about the severity of the influenza season in 2015 and also 2018..$^{7}$ Similar debates have centred on whether 3 -year rolling average figures, which are commonly used in the UK to avoid random fluctuations being overinterpreted, had clouded the importance of 2015 in explaining the overall trends. ${ }^{7}$ It has also been considered important by some to look at whether more deaths in the winter months are responsible for the recent trends. ${ }^{9}$

The range of ways of looking at mortality-including crude weekly and monthly death counts, quarterly age-standardised mortality, annual life expectancy or 3 -year rolling average life expectancy-have generated a lot of debate in the UK about whether the trends are getting worse or better, and therefore how worried we should be about the trends. ${ }^{10} 11$

This paper aims to frame the debate around recent life expectancy trends in the UK by comparing the life expectancy data from 2012 onwards with projected trends using data from earlier time periods. This should reveal the size of the gap between the actual and projected figures, the extent of change in the long-run trends and the lack of importance of data from any single year.

\section{METHODS}

\section{Data source}

We used the annual period life expectancy at birth data for the UK and its nations recently published by the Office for National Statistics (ONS). ${ }^{12}$ Our approach to projections is simpler than that of the ONS in that it does not look at different trends by age group, but the results are very similar. The differences are detailed further in the 'Discussion' section.

\section{Analytical approach}

Ronald Lee co-created the Lee-Carter model for mortality projection ${ }^{13} 14$ in the early 1990s. As a result of analyses by White ${ }^{15}$ and Oeppen and Vaupel, ${ }^{16}$ he subsequently accepted that a much simpler modelling approach is often adequate for life expectancy forecasting. This approach involves modelling life expectancy at birth $\left(e_{0}\right)$ directly, rather than individual age-specific mortality rates $\left(m_{x}\right)$ and quantities derived from them (a 'drift parameter' $k$ ) as in Lee-Carter's original model specification.

Although Lee (2002) presents a number of refinements of a basic linear life expectancy forecast model specification, including models which allow for negative autocorrelation between change in years, the article states that the basic strategy for forecasting should be 'to use the appropriate or preferred equation for $d e_{t} / d t$ [change in life expectancy] to estimate $e 01$ year later, and then continue recursively'. ${ }^{17}$ This is the approach we use in this paper. 


\section{Modelling strategy}

We extracted $e_{0}(s, t)$, the period life expectancy at birth for sex $s$ and time $t$, for each single year between 1980 and 2018 for the UK and each of its nations. We defined $\Delta e_{0}(s, t)$ as the change in life expectancy for sex $s$ from year $t$ to year $t+1$. We plotted both $e_{0}$ against $t$ by $s$, and $\Delta e_{0}$ against $t$ by $s$, to identify appropriate preslowdown time periods, that is, the range of years prior to 2012 (our assumed breakpoint in mortality trends) to use to calibrate projections of life expectancy trends from 2012 to 2018 onwards. Based on these plots and background knowledge, we selected two pre-slowdown periods:

- $P_{1}:$ 1980-2011 inclusive

- $P_{2}:$ 1990-2011 inclusive

For both of these pre-slowdown periods, we calculated the mean annual change observed by sex (ie, $\left.E\left(\Delta e_{0}(t \in P, s)\right)\right)$ and the variance in mean annual changes over the same period (ie, $\operatorname{Var}\left(\boldsymbol{\Delta} e_{0}(t \in P, s)\right)$.

To project forward estimates of life expectancy trends based on pre-slowdown observations in a way that takes into account observed variation in annual changes, we sample and accumulate $k$ draws from normal distributions calibrated on the sample means and variances from the pre-slowdown period $\left(P_{1}\right.$ or $\left.P_{2}\right)$, where $k$ refers to the number of annual periods we want to project forward from 2011. As we want to project forward to 2018, we therefore select $k=7$. This exercise is repeated $m=10,000$ times to allow credible intervals in forecasts to be calculated using a Monte Carlo approach. Life expectancy projections for each year 2012-2018 inclusive are produced by summing up the draws from the first projected period onwards; the life expectancy from 2011 (the last observation in the preslowdown period) is added to these summed values to produce predicted life expectancies rather than cumulative gains or losses in life expectancy since 2011. Algebraically, this can be expressed as follows:

$$
\begin{gathered}
e_{0}^{*}(t=\tau+K)=e_{0}(t=\tau)+\sum_{k=1}^{K} N_{k} \\
N \sim \operatorname{Normal}\left(\mu=E\left(\Delta e_{0}(P), \sigma^{2}=\operatorname{Var}\left(\Delta e_{0}(P)\right)\right)\right)
\end{gathered}
$$

where $\tau$ refers to $2011, K$ the discrete number of periods to forecast after $\tau$ and $\Delta e_{0}(P)$ the series of annual changes over the pre-slowdown period $P$.

As for each sex and number of discrete projection periods $K$ (from 1 to 7 periods), $m$ replicates have been produced, the observed life expectancy $e_{0}(t=\tau+K)$ can be compared against the Monte Carlo distribution of $m$ corresponding projections for the same period $e_{0}^{*}(t=\tau+K)$. This comparison is shown both graphically, using shaded regions to indicate the $90 \%$ and $95 \%$ credible intervals from the projected distributions, and by counting up the proportion of the $m$ projected values which exceed the observed values for each post-2011 period $K$. For both pre-trend periods, $P_{1}$ (1980-2011) and $P_{2}$ (1990-2011), the same random number seed was used. All data preparation and analysis were performed using the $\mathrm{R}$ programming language. ${ }^{18}$ All of the $\mathrm{R}$ code relating to the analysis in this paper is available at https://github.com/JonMinton/bayes_factor_slowdown/blob/ master/scotland_projections.Rmd.

\section{RESULTS}

Steadily increasing trends in period life expectancy were projected for the UK overall and each of its nations using both the longer (1980-2011 inclusive, table 1) or shorter (1990-2011 inclusive, table 2) baseline period (figure 1). The longer baseline period projected a smaller increase in life expectancy than the shorter period, because of more rapid increases from the late 1990s to 2011 than there were during the 1980s and early 1990s. The cones of uncertainty for the UK overall and England were much smaller because there was less year-to-year variation in the baseline period for those countries with larger populations.

The actual life expectancy data for the UK overall and for each of the nations diverged rapidly and consistently from the median projected figures from 2012 to 2018 (figure 1). Although the divergence was similar across all of the nations, the difference from the expected remained within the cone of uncertainty for Northern Ireland, and for some of the estimates for Scotland and Wales, because of the greater imprecision in the estimates for these nations.

Using the projections based on the 1990-2011 baseline, life expectancy in England for females and males was 1.22 and 1.52 years respectively lower than the median projection in 2018 . The equivalent figures for females and males respectively were 1.44 and 0.95 years (Northern Ireland), 1.30 and 1.44 years (Scotland), 1.53 and 1.63 years (Wales) and 1.24 and 1.49 years (UK overall).

Based on the 1990-2011 baseline projections to 2028, an annual increase in life expectancy of 0.33 and 0.44 years for females and males respectively would be required for achievement of the projected median by 2028 in England. The equivalent figures for females and males were 0.35 and 0.37 years (Northern Ireland), 0.40 and 0.35 years (Scotland), 0.35 and 0.42 years (Wales) and 0.33 and 0.43 years (UK overall).

Using the alternative baseline based on the 1980-2011 data, life expectancy in England for females and males was 1.15 and 1.41 years respectively lower than the median projection in 2018. The equivalent figures for females and males respectively were 1.63 and 1.17 years (Northern Ireland), 1.07 and 1.15 years (Scotland), 1.49 and 1.62 years (Wales) and 1.16 and 1.39 years (UK overall). To achieve the projected median for 2028 based on the 1980-2011 baseline data would require annual increases in life expectancy for females and males respectively of 0.31 and 0.41 years (England), 0.40 and 0.43 years (Northern Ireland), 0.29 and 0.36 years (Scotland), 0.34 and 0.41 years (Wales) and 0.31 and 0.40 years (UK overall).

\section{DISCUSSION}

\section{Main results}

Life expectancy trends in the UK overall, and for England, Northern Ireland, Scotland and Wales, diverged between 2012 and 2018 from those experienced previously. Based on the 1990-2011 baseline, life expectancy was lower than the median projection in 2018, for females and males respectively, by 1.22 and 1.52 years (England), 1.44 and 0.95 years (Northern Ireland), 1.30 and 1.44 years (Scotland), 1.53 and 1.63 years (Wales) and 1.24 and 1.49 years (UK overall). To get back to this previous trend by 2028, annual increases in life expectancy for females and males respectively of 0.33 and 0.44 years (England), 0.35 and 0.37 years (Northern Ireland), 0.40 and 0.35 years (Scotland), 0.35 and 0.42 years (Wales) and 0.33 and 0.43 years (UK overall) would be required each year from 2018 . The longer baseline period (1980-2011) projects a slightly lower future life expectancy for Scotland, England and the UK, slightly reducing the gap between the current life expectancies and the projected medians for those populations, because there was a faster period of life expectancy improvement during the late 1990s and 2000s. 
Table 1 Trends in life expectancy at birth for England, Northern Ireland, Scotland, Wales and the UK, 2012-2018, compared with projected trends based on 1980-2011, with projections to 2028

\begin{tabular}{|c|c|c|c|c|c|c|c|c|c|c|c|c|c|c|c|c|c|}
\hline Year & 2012 & 2013 & 2014 & 2015 & 2016 & 2017 & 2018 & 2019 & 2020 & 2021 & 2022 & 2023 & 2024 & 2025 & 2026 & 2027 & 2028 \\
\hline \multicolumn{18}{|l|}{ England males } \\
\hline Median projection & 79.36 & 79.63 & 79.90 & 80.16 & 80.43 & 80.69 & 80.96 & 81.22 & 81.49 & 81.76 & 82.03 & 82.30 & 82.57 & 82.84 & 83.10 & 83.37 & 83.63 \\
\hline Upper 95th percentile & 79.66 & 80.05 & 80.41 & 80.76 & 81.09 & 81.43 & 81.76 & 82.08 & 82.39 & 82.70 & 83.01 & 83.31 & 83.63 & 83.93 & 84.24 & 84.55 & 84.86 \\
\hline Lower 95th percentile & 79.06 & 79.20 & 79.37 & 79.55 & 79.75 & 79.96 & 80.17 & 80.38 & 80.59 & 80.81 & 81.05 & 81.26 & 81.49 & 81.71 & 81.94 & 82.16 & 82.38 \\
\hline Actual trend & 79.26 & 79.27 & 79.51 & 79.34 & 79.52 & 79.59 & 79.55 & & & & & & & & & & \\
\hline \multicolumn{18}{|l|}{ England females } \\
\hline Median projection & 83.16 & 83.36 & 83.56 & 83.76 & 83.96 & 84.15 & 84.35 & 84.54 & 84.74 & 84.94 & 85.14 & 85.34 & 85.54 & 85.74 & 85.94 & 86.13 & 86.33 \\
\hline Upper 95th percentile & 83.52 & 83.87 & 84.18 & 84.48 & 84.75 & 85.04 & 85.31 & 85.57 & 85.82 & 86.07 & 86.33 & 86.56 & 86.82 & 87.06 & 87.31 & 87.56 & 87.81 \\
\hline Lower 95th percentile & 82.80 & 82.85 & 82.92 & 83.02 & 83.14 & 83.26 & 83.40 & 83.52 & 83.65 & 83.79 & 83.96 & 84.08 & 84.24 & 84.38 & 84.54 & 84.68 & 84.82 \\
\hline Actual trend & 82.92 & 82.99 & 83.23 & 82.96 & 83.11 & 83.23 & 83.20 & & & & & & & & & & \\
\hline \multicolumn{18}{|l|}{ Northern Ireland males } \\
\hline Median projection & 78.16 & 78.47 & 78.79 & 79.10 & 79.41 & 79.71 & 80.01 & 80.31 & 80.63 & 80.95 & 81.26 & 81.57 & 81.88 & 82.19 & 82.50 & 82.81 & 83.10 \\
\hline Upper 95th percentile & 78.78 & 79.36 & 79.85 & 80.34 & 80.77 & 81.25 & 81.68 & 82.10 & 82.50 & 82.90 & 83.30 & 83.68 & 84.09 & 84.47 & 84.87 & 85.27 & 85.67 \\
\hline Lower 95th percentile & 77.54 & 77.59 & 77.69 & 77.82 & 77.99 & 78.18 & 78.38 & 78.56 & 78.74 & 78.95 & 79.20 & 79.39 & 79.63 & 79.85 & 80.07 & 80.29 & 80.50 \\
\hline Actual trend & 78.05 & 78.07 & 78.61 & 78.17 & 78.75 & 78.38 & 78.84 & & & & & & & & & & \\
\hline \multicolumn{18}{|c|}{ Northern Ireland females } \\
\hline Median projection & 82.64 & 82.88 & 83.13 & 83.37 & 83.61 & 83.84 & 84.07 & 84.30 & 84.55 & 84.80 & 85.04 & 85.28 & 85.52 & 85.76 & 86.00 & 86.24 & 86.46 \\
\hline Upper 95th percentile & 83.34 & 83.88 & 84.32 & 84.76 & 85.14 & 85.56 & 85.94 & 86.30 & 86.64 & 86.98 & 87.33 & 87.64 & 88.00 & 88.31 & 88.66 & 88.99 & 89.33 \\
\hline Lower 95th percentile & 81.95 & 81.90 & 81.89 & 81.94 & 82.02 & 82.12 & 82.24 & 82.34 & 82.43 & 82.56 & 82.74 & 82.84 & 83.00 & 83.14 & 83.28 & 83.42 & 83.55 \\
\hline Actual trend & 82.26 & 82.22 & 82.38 & 82.22 & 82.27 & 82.43 & 82.44 & & & & & & & & & & \\
\hline \multicolumn{18}{|l|}{ Scotland males } \\
\hline Median projection & 76.74 & 76.99 & 77.23 & 77.48 & 77.72 & 77.96 & 78.20 & 78.43 & 78.68 & 78.93 & 79.17 & 79.42 & 79.66 & 79.91 & 80.15 & 80.39 & 80.62 \\
\hline Upper 95th percentile & 77.18 & 77.61 & 77.98 & 78.35 & 78.68 & 79.04 & 79.37 & 79.69 & 79.99 & 80.30 & 80.61 & 80.90 & 81.22 & 81.51 & 81.82 & 82.12 & 82.42 \\
\hline Lower 95th percentile & 76.31 & 76.37 & 76.46 & 76.58 & 76.72 & 76.88 & 77.05 & 77.20 & 77.35 & 77.53 & 77.73 & 77.89 & 78.08 & 78.26 & 78.44 & 78.62 & 78.79 \\
\hline Actual trend & 76.79 & 77.02 & 77.32 & 76.95 & 76.96 & 77.13 & 77.05 & & & & & & & & & & \\
\hline \multicolumn{18}{|l|}{ Scotland females } \\
\hline Median projection & 81.00 & 81.18 & 81.37 & 81.55 & 81.73 & 81.90 & 82.08 & 82.26 & 82.44 & 82.63 & 82.81 & 82.99 & 83.18 & 83.36 & 83.54 & 83.72 & 83.89 \\
\hline Upper 95th percentile & 81.53 & 81.94 & 82.27 & 82.60 & 82.88 & 83.20 & 83.49 & 83.76 & 84.02 & 84.28 & 84.54 & 84.77 & 85.04 & 85.28 & 85.54 & 85.79 & 86.05 \\
\hline Lower 95th percentile & 80.48 & 80.44 & 80.44 & 80.48 & 80.53 & 80.61 & 80.70 & 80.78 & 80.85 & 80.95 & 81.08 & 81.16 & 81.28 & 81.38 & 81.49 & 81.59 & 81.70 \\
\hline Actual trend & 80.80 & 81.04 & 81.34 & 81.03 & 81.08 & 81.16 & 81.01 & & & & & & & & & & \\
\hline \multicolumn{18}{|l|}{ Wales males } \\
\hline Median projection & 78.34 & 78.60 & 78.85 & 79.10 & 79.36 & 79.60 & 79.85 & 80.09 & 80.35 & 80.61 & 80.86 & 81.11 & 81.37 & 81.62 & 81.87 & 82.12 & 82.35 \\
\hline Upper 95th percentile & 78.96 & 79.48 & 79.91 & 80.35 & 80.72 & 81.13 & 81.51 & 81.87 & 82.21 & 82.55 & 82.90 & 83.22 & 83.57 & 83.89 & 84.24 & 84.57 & 84.91 \\
\hline Lower 95th percentile & 77.72 & 77.72 & 77.75 & 77.83 & 77.94 & 78.07 & 78.21 & 78.34 & 78.46 & 78.62 & 78.81 & 78.94 & 79.12 & 79.28 & 79.45 & 79.60 & 79.76 \\
\hline Actual trend & 78.23 & 78.16 & 78.79 & 78.27 & 78.23 & 78.45 & 78.23 & & & & & & & & & & \\
\hline \multicolumn{18}{|l|}{ Wales females } \\
\hline Median projection & 82.52 & 82.72 & 82.92 & 83.11 & 83.30 & 83.48 & 83.68 & 83.86 & 84.06 & 84.26 & 84.45 & 84.65 & 84.84 & 85.04 & 85.23 & 85.42 & 85.60 \\
\hline Upper 95th percentile & 83.11 & 83.56 & 83.92 & 84.29 & 84.59 & 84.94 & 85.25 & 85.55 & 85.82 & 86.10 & 86.39 & 86.64 & 86.93 & 87.19 & 87.47 & 87.74 & 88.02 \\
\hline Lower 95th percentile & 81.94 & 81.89 & 81.88 & 81.90 & 81.96 & 82.04 & 82.13 & 82.20 & 82.27 & 82.37 & 82.51 & 82.59 & 82.71 & 82.82 & 82.94 & 83.04 & 83.14 \\
\hline Actual trend & 82.09 & 82.13 & 82.61 & 82.03 & 82.42 & 82.39 & 82.19 & & & & & & & & & & \\
\hline \multicolumn{18}{|l|}{ UK males } \\
\hline Median projection & 79.04 & 79.30 & 79.57 & 79.83 & 80.10 & 80.36 & 80.63 & 80.89 & 81.16 & 81.42 & 81.69 & 81.96 & 82.22 & 82.49 & 82.76 & 83.02 & 83.28 \\
\hline Upper 95th percentile & 79.34 & 79.73 & 80.09 & 80.44 & 80.76 & 81.11 & 81.43 & 81.75 & 82.06 & 82.37 & 82.68 & 82.98 & 83.29 & 83.59 & 83.90 & 84.21 & 84.52 \\
\hline Lower 95th percentile & 78.74 & 78.88 & 79.04 & 79.22 & 79.41 & 79.62 & 79.83 & 80.04 & 80.24 & 80.46 & 80.70 & 80.90 & 81.13 & 81.36 & 81.58 & 81.80 & 82.02 \\
\hline Actual trend & 78.95 & 78.98 & 79.25 & 79.04 & 79.21 & 79.28 & 79.24 & & & & & & & & & & \\
\hline \multicolumn{18}{|l|}{ UK females } \\
\hline Median projection & 82.91 & 83.11 & 83.31 & 83.50 & 83.70 & 83.89 & 84.09 & 84.28 & 84.48 & 84.68 & 84.88 & 85.08 & 85.28 & 85.48 & 85.67 & 85.87 & 86.06 \\
\hline Upper 95th percentile & 83.28 & 83.64 & 83.94 & 84.25 & 84.52 & 84.81 & 85.09 & 85.35 & 85.60 & 85.85 & 86.10 & 86.34 & 86.60 & 86.84 & 87.09 & 87.34 & 87.59 \\
\hline Lower 95th percentile & 82.54 & 82.58 & 82.65 & 82.74 & 82.85 & 82.98 & 83.11 & 83.23 & 83.35 & 83.49 & 83.66 & 83.78 & 83.93 & 84.08 & 84.22 & 84.36 & 84.51 \\
\hline Actual trend & 82.66 & 82.74 & 82.99 & 82.71 & 82.87 & 82.98 & 82.93 & & & & & & & & & & \\
\hline
\end{tabular}


Table 2 Trends in life expectancy at birth for England, Northern Ireland, Scotland, Wales and the UK, 2012-2018, compared with projected trends based on 1990-2011, with projections to 2028

\begin{tabular}{|c|c|c|c|c|c|c|c|c|c|c|c|c|c|c|c|c|c|}
\hline Year & 2012 & 2013 & 2014 & 2015 & 2016 & 2017 & 2018 & 2019 & 2020 & 2021 & 2022 & 2023 & 2024 & 2025 & 2026 & 2027 & 2028 \\
\hline \multicolumn{18}{|l|}{ England males } \\
\hline Median projection & 79.37 & 79.66 & 79.94 & 80.23 & 80.51 & 80.79 & 81.07 & 81.35 & 81.64 & 81.93 & 82.21 & 82.49 & 82.78 & 83.06 & 83.35 & 83.63 & 83.91 \\
\hline Upper 95th percentile & 79.68 & 80.09 & 80.46 & 80.83 & 81.17 & 81.54 & 81.88 & 82.22 & 82.54 & 82.87 & 83.20 & 83.51 & 83.85 & 84.16 & 84.49 & 84.82 & 85.15 \\
\hline Lower 95th percentile & 79.07 & 79.23 & 79.41 & 79.61 & 79.83 & 80.05 & 80.28 & 80.50 & 80.73 & 80.96 & 81.22 & 81.44 & 81.69 & 81.93 & 82.17 & 82.41 & 82.65 \\
\hline Actual trend & 79.26 & 79.27 & 79.51 & 79.34 & 79.52 & 79.59 & 79.55 & & & & & & & & & & \\
\hline \multicolumn{18}{|l|}{ England females } \\
\hline Median projection & 83.17 & 83.38 & 83.59 & 83.80 & 84.01 & 84.22 & 84.42 & 84.63 & 84.84 & 85.06 & 85.27 & 85.48 & 85.69 & 85.90 & 86.11 & 86.31 & 86.51 \\
\hline Upper 95th percentile & 83.55 & 83.92 & 84.23 & 84.55 & 84.84 & 85.14 & 85.43 & 85.70 & 85.96 & 86.23 & 86.50 & 86.74 & 87.02 & 87.27 & 87.53 & 87.79 & 88.06 \\
\hline Lower 95th percentile & 82.80 & 82.85 & 82.93 & 83.04 & 83.16 & 83.30 & 83.44 & 83.57 & 83.71 & 83.86 & 84.03 & 84.17 & 84.33 & 84.49 & 84.65 & 84.80 & 84.95 \\
\hline Actual trend & 82.92 & 82.99 & 83.23 & 82.96 & 83.11 & 83.23 & 83.20 & & & & & & & & & & \\
\hline \multicolumn{18}{|l|}{ Northern Ireland males } \\
\hline Median projection & 78.13 & 78.41 & 78.69 & 78.97 & 79.25 & 79.51 & 79.79 & 80.06 & 80.34 & 80.63 & 80.91 & 81.18 & 81.47 & 81.74 & 82.02 & 82.29 & 82.56 \\
\hline Upper 95th percentile & 78.67 & 79.18 & 79.62 & 80.05 & 80.44 & 80.86 & 81.24 & 81.61 & 81.97 & 82.33 & 82.69 & 83.02 & 83.39 & 83.72 & 84.09 & 84.44 & 84.79 \\
\hline Lower 95th percentile & 77.59 & 77.64 & 77.73 & 77.86 & 78.01 & 78.18 & 78.36 & 78.53 & 78.70 & 78.89 & 79.12 & 79.29 & 79.50 & 79.70 & 79.91 & 80.10 & 80.30 \\
\hline Actual trend & 78.05 & 78.07 & 78.61 & 78.17 & 78.75 & 78.38 & 78.84 & & & & & & & & & & \\
\hline \multicolumn{18}{|c|}{ Northern Ireland females } \\
\hline Median projection & 82.61 & 82.83 & 83.04 & 83.25 & 83.47 & 83.67 & 83.88 & 84.08 & 84.30 & 84.52 & 84.73 & 84.94 & 85.16 & 85.37 & 85.58 & 85.79 & 85.99 \\
\hline Upper 95th percentile & 83.28 & 83.77 & 84.18 & 84.58 & 84.92 & 85.31 & 85.65 & 85.98 & 86.28 & 86.59 & 86.91 & 87.19 & 87.51 & 87.79 & 88.11 & 88.41 & 88.71 \\
\hline Lower 95th percentile & 81.95 & 81.89 & 81.87 & 81.90 & 81.96 & 82.04 & 82.14 & 82.21 & 82.29 & 82.40 & 82.55 & 82.63 & 82.76 & 82.88 & 83.00 & 83.11 & 83.23 \\
\hline Actual trend & 82.26 & 82.22 & 82.38 & 82.22 & 82.27 & 82.43 & 82.44 & & & & & & & & & & \\
\hline \multicolumn{18}{|l|}{ Scotland males } \\
\hline Median projection & 76.76 & 77.03 & 77.30 & 77.57 & 77.83 & 78.09 & 78.35 & 78.61 & 78.88 & 79.15 & 79.42 & 79.69 & 79.96 & 80.22 & 80.49 & 80.75 & 81.00 \\
\hline Upper 95th percentile & 77.25 & 77.73 & 78.13 & 78.54 & 78.90 & 79.29 & 79.65 & 80.00 & 80.34 & 80.68 & 81.02 & 81.33 & 81.68 & 81.99 & 82.34 & 82.67 & 83.00 \\
\hline Lower 95th percentile & 76.28 & 76.35 & 76.44 & 76.57 & 76.73 & 76.90 & 77.08 & 77.25 & 77.41 & 77.60 & 77.82 & 77.99 & 78.20 & 78.39 & 78.60 & 78.79 & 78.98 \\
\hline Actual trend & 76.79 & 77.02 & 77.32 & 76.95 & 76.96 & 77.13 & 77.05 & & & & & & & & & & \\
\hline \multicolumn{18}{|l|}{ Scotland females } \\
\hline Median projection & 81.03 & 81.25 & 81.46 & 81.67 & 81.88 & 82.09 & 82.30 & 82.50 & 82.72 & 82.93 & 83.15 & 83.36 & 83.57 & 83.78 & 84.00 & 84.20 & 84.40 \\
\hline Upper 95th percentile & 81.52 & 81.94 & 82.30 & 82.65 & 82.96 & 83.29 & 83.60 & 83.90 & 84.18 & 84.47 & 84.75 & 85.01 & 85.31 & 85.57 & 85.86 & 86.13 & 86.41 \\
\hline Lower 95th percentile & 80.54 & 80.56 & 80.60 & 80.67 & 80.77 & 80.89 & 81.01 & 81.12 & 81.23 & 81.37 & 81.53 & 81.65 & 81.80 & 81.94 & 82.09 & 82.23 & 82.37 \\
\hline Actual trend & 80.80 & 81.04 & 81.34 & 81.03 & 81.08 & 81.16 & 81.01 & & & & & & & & & & \\
\hline \multicolumn{18}{|l|}{ Wales males } \\
\hline Median projection & 78.34 & 78.60 & 78.86 & 79.11 & 79.36 & 79.61 & 79.86 & 80.10 & 80.36 & 80.62 & 80.88 & 81.13 & 81.39 & 81.64 & 81.89 & 82.14 & 82.38 \\
\hline Upper 95th percentile & 78.97 & 79.50 & 79.93 & 80.37 & 80.74 & 81.16 & 81.54 & 81.90 & 82.24 & 82.59 & 82.94 & 83.26 & 83.62 & 83.93 & 84.29 & 84.62 & 84.96 \\
\hline Lower 95th percentile & 77.72 & 77.71 & 77.75 & 77.83 & 77.93 & 78.07 & 78.21 & 78.33 & 78.46 & 78.61 & 78.81 & 78.94 & 79.12 & 79.28 & 79.45 & 79.60 & 79.76 \\
\hline Actual trend & 78.23 & 78.16 & 78.79 & 78.27 & 78.23 & 78.45 & 78.23 & & & & & & & & & & \\
\hline \multicolumn{18}{|l|}{ Wales females } \\
\hline Median projection & 82.53 & 82.73 & 82.93 & 83.13 & 83.33 & 83.52 & 83.72 & 83.91 & 84.12 & 84.32 & 84.52 & 84.72 & 84.92 & 85.12 & 85.32 & 85.52 & 85.70 \\
\hline Upper 95th percentile & 83.09 & 83.54 & 83.90 & 84.26 & 84.57 & 84.92 & 85.23 & 85.53 & 85.81 & 86.09 & 86.37 & 86.63 & 86.93 & 87.18 & 87.47 & 87.75 & 88.02 \\
\hline Lower 95th percentile & 81.97 & 81.94 & 81.94 & 81.98 & 82.05 & 82.14 & 82.24 & 82.32 & 82.40 & 82.51 & 82.66 & 82.75 & 82.88 & 83.00 & 83.12 & 83.23 & 83.35 \\
\hline Actual trend & 82.09 & 82.13 & 82.61 & 82.03 & 82.42 & 82.39 & 82.19 & & & & & & & & & & \\
\hline \multicolumn{18}{|l|}{ UK males } \\
\hline Median projection & 79.05 & 79.33 & 79.61 & 79.89 & 80.17 & 80.45 & 80.73 & 81.00 & 81.29 & 81.57 & 81.85 & 82.13 & 82.41 & 82.69 & 82.97 & 83.25 & 83.52 \\
\hline Upper 95th percentile & 79.36 & 79.77 & 80.14 & 80.51 & 80.85 & 81.21 & 81.55 & 81.88 & 82.20 & 82.53 & 82.86 & 83.17 & 83.50 & 83.81 & 84.14 & 84.46 & 84.79 \\
\hline Lower 95th percentile & 78.74 & 78.90 & 79.07 & 79.27 & 79.47 & 79.70 & 79.92 & 80.14 & 80.36 & 80.59 & 80.84 & 81.06 & 81.30 & 81.54 & 81.78 & 82.01 & 82.25 \\
\hline Actual trend & 78.95 & 78.98 & 79.25 & 79.04 & 79.21 & 79.28 & 79.24 & & & & & & & & & & \\
\hline \multicolumn{18}{|l|}{ UK females } \\
\hline Median projection & 82.92 & 83.13 & 83.34 & 83.55 & 83.76 & 83.97 & 84.17 & 84.38 & 84.59 & 84.81 & 85.02 & 85.23 & 85.44 & 85.65 & 85.86 & 86.06 & 86.26 \\
\hline Upper 95th percentile & 83.31 & 83.68 & 84.00 & 84.32 & 84.61 & 84.92 & 85.20 & 85.48 & 85.74 & 86.01 & 86.28 & 86.53 & 86.81 & 87.05 & 87.32 & 87.58 & 87.85 \\
\hline Lower 95th percentile & 82.54 & 82.59 & 82.66 & 82.77 & 82.88 & 83.02 & 83.16 & 83.29 & 83.42 & 83.57 & 83.75 & 83.88 & 84.04 & 84.20 & 84.36 & 84.51 & 84.66 \\
\hline Actual trend & 82.66 & 82.74 & 82.99 & 82.71 & 82.87 & 82.98 & 82.93 & & & & & & & & & & \\
\hline
\end{tabular}




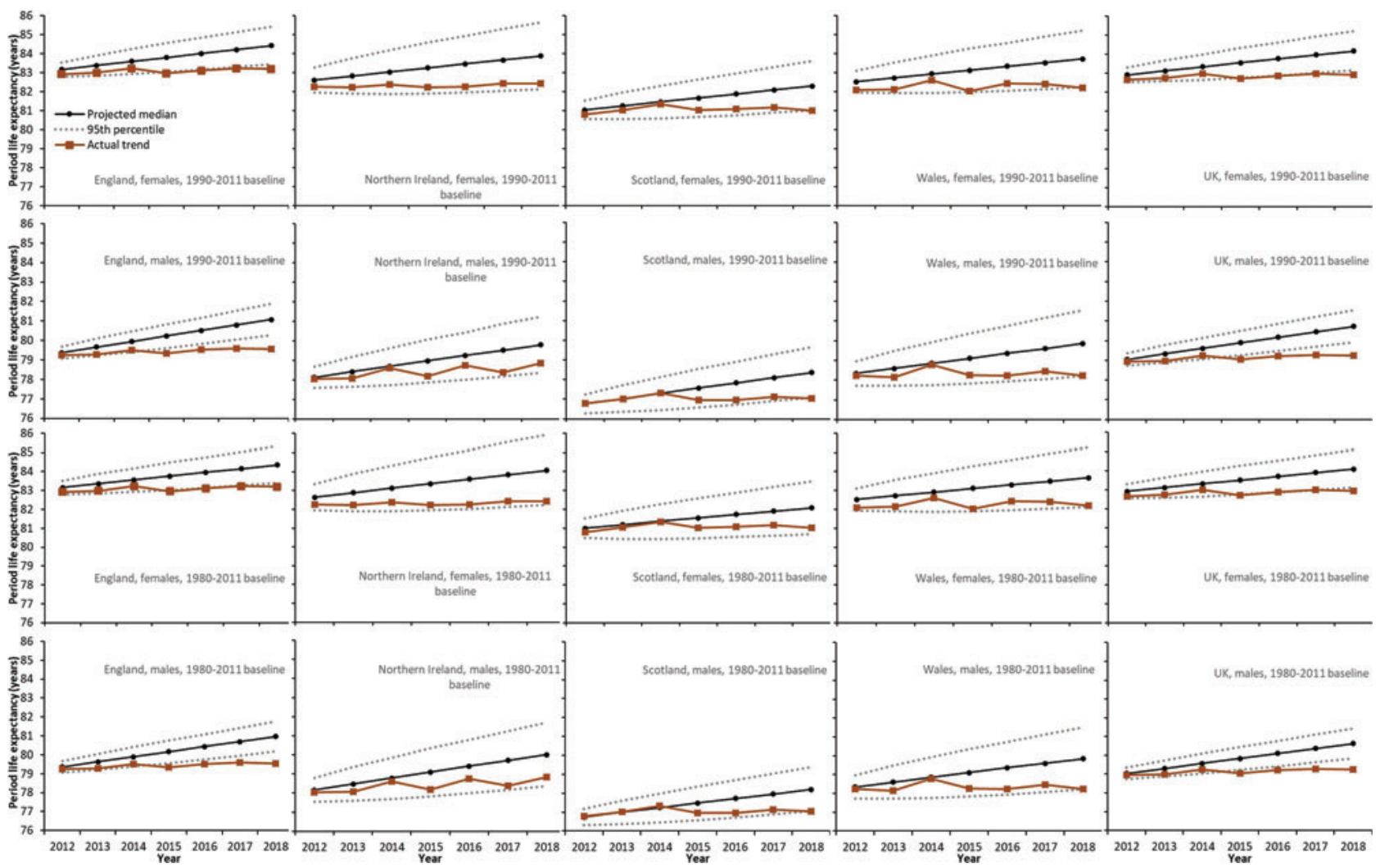

Figure 1 Trends in life expectancy at birth for England, Northern Ireland, Scotland, Wales and the UK, 2012-2018, compared with projected trends based on 1990-2011 (upper two rows) and 1980-2011 (lower two rows).

\section{Strengths and limitations}

Our approach to projecting life expectancy follows common practice and reflects the variance between years for the baseline period. This also provides a cone of uncertainty based on this variance to guide judgement on how likely or otherwise the observed trends are. The cones of uncertainty are wider in Northern Ireland, Scotland and Wales reflecting the smaller population sizes and consequent greater year-to-year variation in the life expectancy figures during the baseline periods. Varying the length of the baseline period slightly changes the median projection, reflecting some, limited, uncertainty in what can be considered the counterfactual expected life expectancy. It is also possible that using a different year for ending the baseline period and conducting the projection would change the results slightly.

We do not consider the projections given here as 'ideal' or 'aspirational' targets, given that they do not consider the need for 'catch-up' for those nations which already experience lower life expectancy such as Scotland, Northern Ireland and Wales. We also do not examine in this paper inequalities in mortality, something that is known to be increasing across Scotland, England and Wales but not Northern Ireland. ${ }^{19-21}$ Narrowing inequalities in mortality is important in its own right, but is therefore also important if the population life expectancy is to be increased rapidly.

\section{How this fits with the existing literature}

Much of the current literature and debate in this area focuses on short-term variations in life expectancy and mortality, and the extent to which it might be explicable by deaths in 2015, rather than the extent to which the recent data have diverged from the previous trends. ${ }^{8}{ }^{11}$ In this paper, we reframe the life expectancy challenge as one of the deviations from a previously improving trend. This is clearly not a single-year problem relating to particularly high mortality over a single winter but instead is a gradual but consistent deviation from previous trends. ${ }^{22}{ }^{23}$ Catching up the lost progress on life expectancy is possible, not least because of the large contribution due to higher mortality among middleaged adults from clearly avoidable causes of death. ${ }^{8}{ }^{24}$ Furthermore, rapid improvements, similar to those required here to achieve catch-up, have been seen in life expectancy in other contexts previously. ${ }^{2}$

The ONS uses a different approach to projecting life expectancy than we used here. This includes the use of trends for agespecific rather than the summary statistic, life expectancy, and also an assumption that age-specific mortality trends will converge over time. Despite this, the projected trends are very similar and it therefore unlikely that the results would change substantially if these alternative methods were adopted. ${ }^{25}$

\section{What are the implications?}

Debate about whether life expectancy in a particular population has increased or declined over a short period of time across the UK misses the important divergence of the trends since 2012, which means that life expectancy is now substantially below the pre-2012 trends. Policy focus and academic commentary should move away from unhelpful debates about the extent to which life expectancy is increasing or decreasing at any particular point of time, and instead focus on the growing divergence of current life expectancy from what should be expected given previous trends. Governments must now prioritise addressing this public health challenge across policy areas to ensure that population well-being is maximised. The need for action to reduce poverty, to protect 
incomes through a generous social security system and to reverse the reductions in the budgets for public services in order to reverse these trends remains stark. ${ }^{26}$

\section{CONCLUSIONS}

Life expectancy trends for the UK and each of its nations have deviated from their previous trends such that life expectancy is now substantially lower than expected. The gap between observed and projected life expectancy has steadily grown after 2011. Policy and academic focus should move away from year-toyear variation and instead aim to change the trajectory to get back to the previous trends.

\section{What is already known on this subject}

- Life expectancy and mortality trends across many highincome countries have changed since around 2011. Substantial debate has centred on whether the year-on-year changes represent a rise or fall in the figures in each country.

\section{What this study adds}

- Examining the trends with annual data for the UK overall and separately for England, Northern Ireland, Scotland and Wales shows that the life expectancy trends are now markedly deviating from the trends up to 2011. The debate on whether or not there is a year-on-year increase or decrease diverts attention from the more substantive problem of the longer-term stalling in trends.

Contributors JM came up with the idea for the study and undertook the analysis. JR curated the data for the study. JM, EF and GM discussed and agreed the methods used. GM drafted the manuscript. All authors provided substantial critical comments and approved the final draft.

Funding All authors are salaried employees of the NHS or National Records of Scotland. No other funding was received for this work. The employing organisations had no role in the writing of this paper or the decision to publish.

Competing interests None.

Patient consent for publication Not required.

Ethics approval No ethical approval was sought or required for this study.

Data sharing statement All data relevant to the study are included in the article or uploaded as supplementary information.

Provenance and peer review Not commissioned; externally peer reviewed.

Open access This is an open access article distributed in accordance with the Creative Commons Attribution Non Commercial (CC BY-NC 4.0) license, which permits others to distribute, remix, adapt, build upon this work non-commercially, and license their derivative works on different terms, provided the original work is properly cited, appropriate credit is given, any changes made indicated, and the use is noncommercial. See: http://creativecommons.org/licenses/by-nc/4.0/.

\section{ORCID iDs}

Jon Minton http://orcid.org/0000-0003-1207-6259

Julie Ramsay http://orcid.org/0000-0001-9362-9729

Gerry McCartney http://orcid.org/0000-0001-6341-3521

\section{REFERENCES}

1 Mackenbach JP. Convergence and divergence of life expectancy in Europe: a centennial view. Eur J Epidemiol 2013;28:229-40.

2 McCartney G, Walsh D, Whyte B, et al. Has Scotland always been the 'sick man' of Europe? An observational study from 1855 to 2006. Eur J Public Health 2012;22:75660.

3 Raleigh V. Trends in life expectancy in EU and other OECD countries: why are improvements slowing? OECD health working papers, no. 108. Paris: OECD Publishing, 2019

4 Leon DA, Jdanov DA, Shkolnikov VM. Trends in life expectancy and age-specific mortality in England and Wales, 1970-2016, in comparison with a set of 22 high-income countries: an analysis of vital statistics data. Lancet Public Health 2019;4:e575-e82.

5 Fenton L, Minton J, Ramsay J, et al. Recent adverse mortality trends in Scotland: comparison with other high-income countries. BMJ Open 2019;9:e029936.

6 Murphy M. Stalling of mortality in the United Kingdom and Europe: an analytical review of the evidence. London: London School of Economics, 2019.

7 Baker A, Fitzpatrick J, Ege F. Why have increases in life expectancy slowed down in England? London: Public Health England, 2018.

8 A review of recent trends in mortality in England. London: Public Health England, 2018. Available https://assets.publishing.service.gov.uk/government/uploads/system/ uploads/attachment_data/file/827518/Recent_trends_in_mortality_in_England.pdf

9 Murphy M. The data behind mortality trends: explaining the recent improvement in mortality in England. London: London School of Economics. Available https://blogs. Ise. ac.uk/politicsandpolicy/explaining-the-recent-improvement-in-mortality-in-england Ion (accessed 25 Nov 2019).

10 Raleigh V, Goldblatt P Life expectancy in England: what's going on? Available https:// blogs.bmj.com/bmj/2019/10/01/life-expectancy-in-england-whats-going-on/

11 Dorling D. Austerity bites: falling life expectancy in the UK. Available https://blogs.bmj. com/bmj/2019/03/19/danny-dorling/

12 Single-year life tables, UK: 1980-2018. London: ONS, 2019. Available https://www. ons.gov.uk/peoplepopulationandcommunity/birthsdeathsandmarriages/lifeexpectan cies/datasets/singleyearlifetablesuk1980to2018/on (accessed 11 Nov 2019).

13 Lee R. Mortality forecasts and linear life expectancy trends. In: Bengtsson T, Keilman N, eds. Old and new perspectives on mortality forecasting. demographic research monographs (a series of the Max Planck Institute for Demographic Research). Cham: Springer, 2019.

14 Lee RD, Carter LR.Modeling and forecasting U.S. mortality. J Am Stat Assoc 1992;87:659-71.

15 White KM. Longevity advances in high-income countries, 1955-96. Popul Dev Rev 2004;28:59-76.

16 Oeppen J, Vaupel JW. Broken limits to life expectancy. Science 2002;296:1029-31.

17 Lee R. Old and new perspectives on mortality forecasting. In: Bengtsson T, Keilman N, eds. Mortality forecasts and linear life expectancy trends. New York: Springer, 2019.

18 R Core Team: R: a language and environment for statistical computing. Vienna, Austria: R Foundation for Statistical Computing, 2013

19 Fenton L, Wyper GM, McCartney G, et al. Socioeconomic inequality in recent adverse all-cause mortality trends in Scotland. J Epidemiol Community Health 2019;73:971-974.

20 Health inequalities annual report 2019. Belfast: Department of Health, 2019. Available https://www.health-ni.gov.uk/publications/health-inequalities-annual-report-2019/on (accessed 25 Nov 2019).

21 Office for National Statistics (ONS). Health state life expectancies by national deprivation deciles, England and Wales: 2015 to 2017. London: ONS, 2019: Available https://www.ons.gov.uk/peoplepopulationandcommunity/healthandsocialcare/healthi nequalities/bulletins/healthstatelifeexpectanciesbyindexofmultipledeprivationimd/ 2015to2017/on (accessed 25 Nov 2019).

22 Dorling D, Gietel-Basten S. Life expectancy in Britain has fallen so much that a million years of life could disappear by 2058. Why? The conversation. Available https:// theconversation.com/life-expectancy-in-britain-has-fallen-so-much-that-a-millionyears-of-life-could-disappear-by-2058-why-88063 (accessed 29 Nov 2017).

23 Marshall L, Finch D, Cairncross L, et al., Mortality and life expectancy trends in the UK: stalling progress. London: Health Foundation, 2019.

24 Ramsay J, Minton J, Fischbacher C, et al. How have changes in death by cause and age group contributed to the recent stalling of life expectancy gains in Scotland? Comparative decomposition analysis of mortality data, 2000-02 to 2015-17. Pre-print ahead of publication. Charlottesville, Virginia, USA: OSF preprints, 2019. Available https://osf.io/preprints/socarxiv/q8rme/

25 National population projections, mortality assumptions: 2018-based. London: ONS, 2019.

26 McCartney G. Recent mortality trends. Glasgow: ScotPHO, 2019. Available at: www. scotpho.org.uk/population-dynamics/recent-mortality-trends/. 